\title{
Lifestyle, medication and socio- demographic determinants of mental and physical health-related quality of life in people with multiple sclerosis
}

George A Jelinek*, Alysha M De Livera, Claudia H Marck, Chelsea R Brown, Sandra L Neate, Keryn L Taylor and Tracey J Weiland

\begin{abstract}
Background: Health-related quality of life (QOL) is a key outcome for people with multiple sclerosis (MS). While modifiable lifestyle factors, like smoking, physical activity and vitamin D, have strong associations with development and progression of MS, few studies have examined such associations with QOL.

Methods: Using patient-reported data from 2312 people with MS from 54 countries, regression models explored associations of socio-demographic, therapeutic and lifestyle factors with QOL, using the Multiple Sclerosis Quality of Life-54 (MSQOL-54).

Results: Participants were on average 45.6 years old, $82.4 \%$ women, mostly partnered (74.1\%), with a university degree (59.5\%). Controlling for socio-demographic factors and disability, factors associated with better physical health composite (PHC) (on a 100 point scale) were: moderate and high physical activity compared to low (5.9 [95\% confidence interval: 4.2, 7.6] and 9.9 [Cl: 8.1, 11.6] points higher score respectively); non-smoking compared to current smoking (4.6 points [Cl: 2.4, 6.7]); better diet (per 10 points on the 100 point Diet Habits Questionnaire scale (DHQ) 1.6 points [Cl: 1.0, 2.2] points); normal body mass index (BMI) versus overweight or obese (2.1 points [Cl: 0.4, 3.7] and 2.4 points [Cl: $0.5,4.3]$ ); fewer comorbidities (4.4 points [Cl: $3.9,4.9]$ ); and not taking a disease-modifying drug (DMD) (2.1 points [Cl: 0.7, 3.4]).

Better mental health composite (MHC) determinants were: moderate and high physical activity compared to low (4.0 points [Cl: 2.0, 6.0] and 5.7 points [Cl: 3.5, 8.0]); non-smoking compared to current (6.7 points [Cl: 4.1, 9.3]); better diet (2.8 points [Cl: 1.9, 3.5]); normal BMl versus overweight or obese (3.1 points [Cl: 1.1, 5.1] and 3.5 points [Cl: 1.3, 5.7]); meditating regularly (2.2 points [Cl: 0.2, 4.2]); and no DMD use (2.9 points [Cl: 1.3, 4.6]).

Conclusions: While causality cannot be concluded from cross-sectional data, the associations between modifiable lifestyle factors and QOL suggest significant potential for secondary prevention of the known deterioration of QOL for people with MS through lifestyle risk factor modification.
\end{abstract}

Keywords: Multiple sclerosis, Quality of life, Determinants, Epidemiology

* Correspondence: g.jelinek@unimelb.edu.au

Neuroepidemiology Unit, Melbourne School of Population and Global

Health, The University of Melbourne, Melbourne, VIC 3010, Australia 


\section{Background}

Multiple sclerosis (MS) is increasingly recognized as a disease with modifiable lifestyle components influencing development and progression [1] that significantly impairs health-related quality of life (QOL) [2, 3]. QOL has been an important component of health status since the early 1980s [4], initially describing generic physical and mental health status in chronic disease, soon adapted to suit particular illnesses [5], including MS [6]. QOL is a key outcome for people with MS [7] that needs to be measured in clinical studies $[8,9]$, may predict the course of disability [10-12], and should be used more widely by clinicians [10], potentially forming the main objective of management [13].

While studies have highlighted the importance of psycho-social issues in determining QOL in MS [13, 14], particularly depression and fatigue $[15,16]$, there has been little research on associations of lifestyle and sociodemographic factors with physical and mental QOL. Potentially determining these associations may allow clinicians to provide evidence-based advice to people with MS on the relative importance of modifiable lifestyle risk factors that should be prioritized for optimal QOL. Many of these factors are associated with QOL and premature death in the general population [17], but there has been conflicting advice regarding diet, stress reduction and other lifestyle behaviours for the MS population. Additionally, currently available disease-modifying drugs (DMDs) have been shown to reduce relapse rate and in some cases slow progression to disability, but there has been conflicting evidence about their effects on QOL, varying from medication to medication, largely related to the issue of side effects $[9,18]$.

Our previous research has separately examined associations of a number of individual lifestyle risk factors with QOL in a large international sample of people with MS, allowing detailed analysis of the relationship between QOL and diet [19] including specific dietary components [20], latitude and vitamin D supplementation [21], physical activity [22], alcohol consumption and cigarette smoking [23], and body mass index (BMI) and number of comorbidities [24], as well as DMD use [25]. These studies did not however allow comparison of the relative magnitude of these associations while mutually adjusting for other modifiable lifestyle factors, medication use and potentially related socio-demographic factors. Such evidence will pave the way for research both to verify and trial these lifestyle determinants in suitably designed intervention studies, and to potentially design and refine treatment programs to integrate medication and lifestyle risk factor modification into secondary preventive approaches.

In this study, using patient-reported data from the Health Outcomes and Lifestyle In a Sample of people with MS (HOLISM) Study [26], we examined a full suite of mutually adjusted lifestyle and socio-demographic factors in this large international sample of people with MS, allowing evaluation of the relative magnitude of associations between lifestyle, medication and sociodemographic factors, and physical and mental QOL.

\section{Methods}

\section{Participants and data collection}

The HOLISM study has been described in detail elsewhere [26]. In brief, participants with definite or possible MS were approached through online forums and websites to undertake a cross-sectional survey using Survey Monkey ${ }^{\bullet}$. Respondents providing consent completed an online questionnaire incorporating validated tools where possible. Demographic factors included age, gender, marital status, educational status, and occupational status using researcher-devised items. Disability was measured with Patient Determined Disease Steps (PDDS) [27] and co-morbidities with The SelfAdministered Comorbidity Questionnaire (SCQ) [28]. Body mass index (BMI) was calculated according to the World Health Organisation (WHO) criteria ( $<20=$ underweight, $20-25=$ normal weight, $25-30=$ overweight and $>30=$ obese). Dietary Habits Questionnaire (DHQ) [29], designed to measure diet according to cardiovascular rehabilitation guidelines, was modified slightly to assess diet on a scale of $0-100$. Social support was measured with the Single Item Measure of Social Support [30].

Level of regular physical activity (low, moderate and high) was assessed using the International Physical Activity Questionnaire (IPAQ) [31]. The IPAQ categories briefly represented the following: high active meant vigorous-intensity activity on at least 3 days, or 7 days of walking, or moderate or vigorous activity; moderately active meant 3 or more days of vigorous activity of at least $20 \mathrm{~min}$ per day; or 5 or more days of moderate or higher intensity activity or walking of at least 30 min per day; and low active meant no or some activity. Omega-3 and vitamin D supplementation (low [average daily dose <5000 IU], high [average daily dose $\geq 5000$ IU]), meditation practice, level of alcohol consumption (low [ $<15 \mathrm{~g} /$ week], moderate [up to $30 \mathrm{~g} /$ day for women and $45 \mathrm{~g} /$ day for men], or high) and current smoking status were assessed using researcher-devised items. Current use of DMDs was assessed using researcher-devised questions [25].

\section{Exclusion criteria}

The initial dataset consisted of 3132 people with definite or possible MS. Of these, 663 who did not have confirmed MS and 157 not providing adequate information were excluded, leaving 2312 individuals for analyses. 


\section{Measuring QOL}

The Multiple Sclerosis Quality of Life (MSQOL-54) Instrument [6] was used as a quantitative measure of physical health-related QOL (Physical Health Composite Score or PHC) and mental health-related QOL (Mental Health Composite Score or MHC). The MSQOL-54, developed from the 36 item short-form health survey (SF-36) to measure QOL in people with MS, is sound psychometrically, in widespread use and available in many languages [10].

\section{Statistical analysis}

Data were analysed using Stata, V12 (StataCorp, College Station, Texas, USA) and R (R Foundation for Statistical Computing, Vienna, Austria). Categorical, continuous, and discrete data were presented as frequency (percentages), mean (standard deviation) and median (25th-75th percentile) respectively.

\section{Main analysis}

To explore associations of modifiable and nonmodifiable risk factors with QOL, using HOLISM variables and our subject-matter knowledge [19-25], we devised a causal outline to develop clinically meaningful multivariable regression models separately for PHC and MHC, with mutual adjustment for lifestyle risk factors, DMD use and socio-demographics. Complete case analysis was restricted to participants with available data.

\section{Sensitivity analyses \\ Multiple imputation}

Analyses were undertaken using multiple imputation to account for missing data. Fully Conditional Specification [32] was used with a single imputation model consisting of the variables in Table 1 . To improve performance of the imputation model [33], some of these variables were used as auxiliary variables (variables not included in the analysis model, but either correlated with the missing variables or associated with missingness of the variables). Fifty multiply imputed datasets were created, and results from these 50 datasets combined using Rubin's rules [33].

\section{Re-weighted PHC}

We also performed a re-weighted analysis in order to explore the effect of the missing sexual health component. While all variables had a relatively low percentage of missing values $(<5 \%)$, PHC was missing in $12.6 \%$ of cases, mostly $(84 \%)$ due to participants not disclosing sexual health data. To explore the effect of inclusion of individuals whose sexual health component was excluded in calculating PHC, we carried out a secondary analysis using multivariable regression, after calculating a re-weighted PHC that excluded the sexual health function.

\section{Results}

\section{Sample characteristics}

Characteristics of outcome, modifiable and nonmodifiable variables are summarised in Table 1. Our study sample of people with MS from 54 countries, predominantly North America, aged on average in their mid-forties, with an unusually high ratio (over 4:1) of women, was well educated with healthy lifestyle habits. This likely reflects selection bias in sampling relatively health-literate people with MS engaged in web-based groups seeking information about health. Their diet was healthy in terms of complying with a cardiovascular risk-reduction diet. There was a low proportion of smokers with few heavy alcohol drinkers, a high proportion supplemented with vitamin D and omega 3s, nearly a third meditated regularly, and the majority engaged in moderate to high physical activity. A little over half were currently using a DMD.

\section{Determinants of QOL}

Table 2 presents associations between modifiable factors and $\mathrm{PHC}$ and $\mathrm{MHC}$ using complete case analysis. Noteworthy associations are bolded. While we have previously examined the associations of each of the variables separately with QOL [19-25], these regression models allowed us to determine associations of each modifiable factor with QOL in the context of all other stable and modifiable factors. While there is no definite agreement on the magnitude of MSQOL-54 score difference that constitutes a clinically relevant difference, as it is derived from the SF-36, and a 5 point difference on this scale has previously been considered to be clinically significant [34], this level of difference was considered a convenient approximation.

\section{Physical health composite}

Those with moderate and high, compared with low, physical activity scored approximately 6 points and 10 points higher respectively on the PHC; not smoking versus currently smoking was associated with 4-5 points better PHC; improved diet of around 30 points on the 100 point DHQ was associated with a clinically relevant 5 points higher PHC; and flaxseed oil supplementation compared to none was associated with around a 2-3 point increment, although significance was marginal and disappeared on multiple imputation.

Of relatively stable but also potentially modifiable factors, number of comorbidities had a strong association, with one less comorbidity associated with 4-5 points higher $\mathrm{PHC}$, along with having two or more support people at around 3 points higher QOL compared to one or none. In keeping with recent research showing higher relapse rate [21,35] and disability [35] with increasing latitude, our data showed 1-2 points lower PHC for 
Table 1 Characteristics of outcome, modifiable and stable variables

\begin{tabular}{|c|c|c|}
\hline Variables & & Value $(n=2312)$ \\
\hline \multicolumn{3}{|l|}{ Outcome variables } \\
\hline \multirow[t]{2}{*}{ MSQOL } & Physical health composite $^{a}$ & $59.0(21.5)$ \\
\hline & Mental health composite ${ }^{a}$ & $66.6(21.4)$ \\
\hline \multicolumn{3}{|l|}{ Modifiable variables } \\
\hline \multicolumn{2}{|l|}{ Latitude (degrees) ${ }^{a}$} & $41.0(8.7)$ \\
\hline \multicolumn{2}{|l|}{$\operatorname{Diet}(\mathrm{DHQ} \text { total) })^{a}$} & $78.9(12.1)$ \\
\hline \multicolumn{2}{|l|}{ Current smoker ${ }^{b}$} & $268 / 2289(11.7)$ \\
\hline \multirow[t]{3}{*}{ Alcohol consumption ${ }^{b}$} & Low & $\begin{array}{l}1398 / 2275 \\
(61.5)\end{array}$ \\
\hline & Moderate & $858 / 2275(37.7)$ \\
\hline & High & 19/2275 (0.8) \\
\hline \multirow[t]{2}{*}{$\begin{array}{l}\text { Vitamin D } \\
\text { supplementation }\end{array}$} & Low & $\begin{array}{l}1747 / 2194 \\
(79.6)\end{array}$ \\
\hline & High & 447/2194 (20.4) \\
\hline \multirow[t]{3}{*}{ Exercise $(I P A Q)^{b}$} & Low & $922 / 2232(41.3)$ \\
\hline & Moderate & $707 / 2232(31.7)$ \\
\hline & High & $603 / 2232(27.0)$ \\
\hline \multirow{4}{*}{$\begin{array}{l}\text { Omega } 3 \\
\text { supplementation }\end{array}$} & None & $806 / 2198(36.7)$ \\
\hline & Flaxseed only & 204/2198 (9.3) \\
\hline & Fish oil only & $793 / 2198(36.0)$ \\
\hline & Both & $395 / 2198(18.0)$ \\
\hline \multirow[t]{2}{*}{ Meditation ${ }^{b}$} & $\begin{array}{l}\text { Never or less than once a } \\
\text { week }\end{array}$ & $\begin{array}{l}1568 / 2243 \\
(69.9)\end{array}$ \\
\hline & Once a week or more & $675 / 2243(30.1)$ \\
\hline \multirow[t]{4}{*}{$B M I^{b}$} & Obese & 439/2284 (19.2) \\
\hline & Overweight & $521 / 2284(22.8)$ \\
\hline & Normal & $\begin{array}{l}1230 / 2284 \\
(53.9)\end{array}$ \\
\hline & Underweight & $94 / 2284(4.1)$ \\
\hline \multirow{2}{*}{$\begin{array}{l}\text { Number of support } \\
\text { people }\end{array}$} & One or none & $596 / 2224(26.8)$ \\
\hline & Two or more & $\begin{array}{l}1628 / 2224 \\
(73.2)\end{array}$ \\
\hline \multicolumn{3}{|l|}{ Socio-demographics } \\
\hline \multicolumn{2}{|l|}{$\mathrm{Age}^{a}$} & $45.6(10.6)$ \\
\hline Gender ${ }^{b}$ & Male & $403 / 2288(17.6)$ \\
\hline \multirow[t]{4}{*}{ Employment $^{b}$} & Employed full or part time & $\begin{array}{l}1323 / 2256 \\
(55.3)\end{array}$ \\
\hline & Student or stay at home carer & $244 / 2256(10.2)$ \\
\hline & Unemployed & $175 / 2256(7.8)$ \\
\hline & $\begin{array}{l}\text { Retired due to age or } \\
\text { disability }\end{array}$ & $602 / 2256(26.7)$ \\
\hline \multirow[t]{3}{*}{ Marital status ${ }^{b}$} & Partnered & $\begin{array}{l}1691 / 2281 \\
(74.1)\end{array}$ \\
\hline & Single & $327 / 2281(14.4)$ \\
\hline & Separated & $263 / 2281(11.5)$ \\
\hline
\end{tabular}

Table 1 Characteristics of outcome, modifiable and stable variables (Continued)

\begin{tabular}{lll}
\hline Education level $^{b}$ & Didn't complete high school & $46 / 2303(2.0)$ \\
& Completed high school/trade & $886 / 2303(38.5)$ \\
& Completed bachelor/higher & $1371 / 2303$ \\
& degree & $(59.5)$ \\
& & $1(0,2)$ \\
Number of $_{\text {comorbidities }^{c}}$ & & \\
Disability scale $^{b}$ & Normal to some & $1267 / 2299$ \\
& & $(55.1)$ \\
& Gait/cane & $792 / 2299(34.5)$ \\
& Major mobility & $240 / 2299(10.4)$ \\
Years since diagnosis & & $6(3,12)$ \\
Country of origin & Australasia & $808 / 2312(34.9)$ \\
& Europe & $606 / 2312(26.2)$ \\
& North America & $841 / 2312(36.4)$ \\
& Other & $57 / 2312(2.5)$ \\
DMD use & Yes & $1096 / 2312$ \\
& & $(51.4)$
\end{tabular}

${ }^{a}$ Values are mean (SD), balues are number (\%), 'Values are median (25th-75th percentile), Denominators vary reflecting number of respondents completing each item

every 10 degrees in latitude further from the equator, an association that, while potentially modifiable, may not be of clinically relevant magnitude. Those with normal BMI compared with overweight or obesity had a 2-3 point better PHC. Higher education was associated with around 5 points better QOL. We found no significant association between alcohol intake and QOL, despite having previously found a positive association when examining this factor individually [23]. Currently taking a DMD was associated with around a 2 point lower $\mathrm{PHC}$.

\section{Mental health composite}

Smoking was significantly associated, with non-smokers having 6-7 points better MHC than smokers. Improved diet of around 20 points was associated with a clinically relevant 5-6 points higher MHC; moderate compared with low exercise was associated with a 4 point increment, and high versus low around 6 points. Meditating once a week or more was associated with around 2 points better QOL compared with not.

Of relatively stable socio-demographic factors, employment was associated with 9-10 points higher MHC for those employed, and 5-7 points for retirees and students compared to those unemployed, and 6-7 points higher score for those with two or more support people. Those who were partnered had around 5 points better QOL than those not. Normal BMI was associated with 3-4 points better MHC compared with overweight or obesity. Taking a DMD was associated with around a 3 points worse MHC. 
Table 2 Associations between modifiable factors and PHC and MHC obtained from multivariable regression models using complete case analyses

\begin{tabular}{|c|c|c|c|c|c|}
\hline Variables & & $\begin{array}{l}\text { Physical Health Composite } \\
\text { Coefficient }(95 \% \text { Cl) }\end{array}$ & $p$-value & $\begin{array}{l}\text { Mental Health Composite } \\
\text { Coefficient }(95 \% \mathrm{Cl})\end{array}$ & $p$-value \\
\hline Latitude (per 10 degrees) & & $-1.3(-2.0,-0.5)$ & 0.001 & $-0.8(-1.9,0.1)$ & 0.1 \\
\hline \multirow[t]{4}{*}{$B M I$} & Normal & reference & & & \\
\hline & Underweight & $0.2(-3.2,3.7)$ & 0.9 & $1.5(-2.8,5.9)$ & 0.5 \\
\hline & Overweight & $-2.1(-3.7,-0.4)$ & 0.02 & $-3.1(-5.1,-1.1)$ & 0.002 \\
\hline & Obese & $-2.4(-4.3,-0.5)$ & 0.005 & $-3.5(-5.7,-1.3)$ & 0.002 \\
\hline \multirow[t]{3}{*}{ Alcohol consumption } & Low & reference & & & \\
\hline & Moderate & $0.3(-7.8,8.3)$ & 0.9 & $0.9(-7.8,9.6)$ & 0.8 \\
\hline & High & $-2.1-(-10.1,5.9)$ & 0.6 & $-1.8(-10.6,6.8)$ & 0.7 \\
\hline Number of comorbidities & & $-4.4(-4.9,-3.9)$ & $<0.001$ & & \\
\hline Diet: DHQ total (per 10 points) & & $1.6(1.0,2.2)$ & $<0.001$ & $2.8(1.9,3.5)$ & $<0.001$ \\
\hline Current smoker & & $-4.6(-6.7,-2.4)$ & $<0.001$ & $-6.7(-9.3,-4.1)$ & $<0.001$ \\
\hline \multirow[t]{2}{*}{ Vitamin D supplementation } & Low & reference & & & \\
\hline & High & $1.4(-0.2,3.1)$ & 0.1 & $-0.04(-2.1,2.0)$ & 0.9 \\
\hline \multirow[t]{4}{*}{ Omega 3 supplementation } & None & reference & & & \\
\hline & Flaxseed only & $2.5(0.0,5.1)$ & 0.05 & $2.1(-1.0,5.2)$ & 0.2 \\
\hline & Fish oil only & $1.0(-0.6,2.6)$ & 0.2 & $1.0(-0.9,3.0)$ & 0.3 \\
\hline & Both flaxseed and fish oil & $2.0(-0.1,4.1)$ & 0.06 & $0.4(-2.2,3.0)$ & 0.8 \\
\hline \multirow[t]{3}{*}{ Exercise (IPAQ) } & Low & reference & & & \\
\hline & Moderate & $5.9(4.2,7.6)$ & $<0.001$ & $4.0(2.0,6.0)$ & 0.001 \\
\hline & High & $9.9(8.1,11.6)$ & $<0.001$ & $5.7(3.5,8.0)$ & $<0.001$ \\
\hline \multirow[t]{2}{*}{ Meditation frequency } & Never or < once a week & reference & & & \\
\hline & Once a week or more & $-.5(-2.0,1.0)$ & 0.7 & $2.2(0.2,4.2)$ & 0.03 \\
\hline \multirow[t]{2}{*}{ Number of support people } & None or one & reference & & & \\
\hline & Two or more & $3.1(1.6,4.6)$ & $<0.001$ & $6.7(4.9,8.5)$ & $<0.001$ \\
\hline \multirow[t]{3}{*}{ Marital status } & Single & & & reference & \\
\hline & Partnered & & & $4.7(2.4,7.0)$ & $<0.001$ \\
\hline & Separated & & & $1.8(-1.4,5.0)$ & 0.3 \\
\hline \multirow[t]{4}{*}{ Employment status } & Unemployed & & & reference & \\
\hline & Student or stay at home carer & & & $7.0(3.2,10.9)$ & $<0.001$ \\
\hline & Employed full or part time & & & $9.4(6.3,12.5)$ & $<0.001$ \\
\hline & Retired due to age or disability & & & $4.8(1.5,8.1)$ & 0.005 \\
\hline \multirow[t]{3}{*}{ Education level } & Didn't complete high school & reference & & & \\
\hline & High school and/or trade & $3.6(-1.1,8.3)$ & 0.14 & & \\
\hline & Bachelor or higher degree & $4.9(0.2,9.6)$ & 0.04 & & \\
\hline DMD use & Yes & $-2.1(-3.4,-0.7)$ & 0.003 & $-2.9(-4.6,-1.3)$ & 0.002 \\
\hline
\end{tabular}

${ }^{a, b}$ Models were adjusted for gender and disability level (age was excluded as in this sample age was collinear with disability level). ${ }^{\mathrm{a}}$ The complete case analysis consisted of $76 \%$ of individuals. ${ }^{\text {b}}$ The complete case analysis consisted of $82 \%$ of the individuals. Number of comorbidities which included measures of the MHC including depression was not included in this model

\section{Sensitivity analyses}

The characteristics of individuals with PHC missing compared to individuals with the PHC were explored (Additional file 1: Table S1). Those with PHC missing were older, female and either single or separated. Variables age, marital status, employment status and
MHC were used as auxiliary variables for analysing $\mathrm{PHC}$, and variables age, education status, number of comorbidities and PHC for MHC. Hence, a single imputation model consisting of all variables was used for multiple imputation within Fully Conditional Specification. 


\section{Multiple imputation}

Associations between modifiable factors and $\mathrm{PHC}$ and MHC obtained using multiple imputation to account for missing values, were essentially consistent with complete case analysis (Additional file 1: Table S2).

\section{Re-weighted PHC}

Results from the multivariable model that included individuals with missing sexual health data were broadly consistent with multiple imputation and complete case analysis (Additional file 1: Table S3).

\section{Discussion}

Our study, with participants exhibiting a full range of exposures to lifestyle factors, and around half not taking a DMD, provided an important opportunity to investigate the relationship of lifestyles ranging from poor to very healthy, controlling for DMD use, with QOL outcomes in MS. The cohort had better than average health status, reflected in body weight, with BMI considerably lower than current Western norms, and only one in ten of the sample with major mobility issues. In turn, this may account for the relatively high physical and mental QOL of the group overall, comparable to a recent Canadian cohort of people with 'benign' MS [36].

While causality cannot be concluded from our crosssectional study, the demonstrated associations of modifiable lifestyle factors with QOL highlight the potential for secondary prevention of the known deterioration of QOL for people with MS through lifestyle risk factor modification. Of factors readily modifiable, cessation of cigarette smoking offers enormous potential benefits to both mental and physical health status of people with MS in addition to its general health benefits. Similarly, while reverse causality may have contributed to the magnitude of effect, a potential minimized by controlling for disability, regular moderate or vigorous exercise warrants recommendation where appropriate in view of the strength of the association with mental and particularly physical QOL, and its known beneficial effect on general health.

Traditionally, people with MS have been advised that dietary change has no proven benefit; in contrast, our data show significantly better QOL for those eating a better diet in line with current cardiovascular recommendations that promote a wholefood diet with reductions in saturated fat intake and increased consumption of fruit, vegetables and fish [37]. Our previous research focusing solely on diet showed these particular individual dietary factors had the strongest associations with the health of people with MS [19]. In the current study, around 20 points increase on the 100 point DHQ scale was associated with clinically relevant higher mental health QOL and 30 point increase with higher physical
QOL. Twenty to 30 points improvement appears quite feasible in terms of potential dietary change, representing a change from a relatively typical modern Western diet to a cardiovascular-health diet.

Our study both supported previously described associations of relatively stable socio-demographic factors with physical and mental QOL of people with MS [38], and revealed new independent associations of significant magnitude of several important modifiable lifestyle determinants. This supports further epidemiological research in validating these factors, and clinical research targeting these lifestyle factors in suitable trials. It has already been shown for example that smoking cessation after MS diagnosis results in a highly significant delay to reaching a progressive phase of the disease of around eight years [39]; presumably this translates to benefits for QOL, and this warrants further study.

While the adoption of healthy lifestyle behaviours may be good for the health status of a person with MS, many would assume that these changes, such as increasing exercise, quitting smoking and improving diet, are difficult to initiate and maintain. Our findings that both mental and physical QOL are better with healthier lifestyle behaviours may provide motivation for people with MS adopting healthy lifestyles and clinicians to recommend such changes. People simply feel better.

QOL is a complex construct. There is an inter-play between psychosocial factors such as depression and social isolation, stress, and locus of control or self-efficacy, as well as immune regulation, disease progression and QOL for people with MS [40]. Plausible biological pathways explain how modifiable lifestyle factors may potentially influence many parts of this equation both directly and indirectly, affecting not only immune function and disease activity directly [41], but also mood, coping mechanisms and sense of control over the illness.

Adopting healthy behaviours may be indirectly associated with QOL, as an externally oriented locus of control, with a feeling of being unable to influence health outcomes, predicts worse disability but also depression and fatigue [42], both determinants of QOL in their own right, and both strongly associated with the lifestyle factors examined here $[43,44]$. Having healthy behaviours may be associated with positive orientation of locus of control, with attendant benefits in motivation to access health information and better adherence to treatment [42]. Where studied, the great majority of people with MS have an external locus of control, a proportion that increases with disease duration [45].

Our study shows that smoking cessation, healthy diet and regular exercise appear to be key targets for lifestyle recommendations in people with MS, whether or not they take a DMD. While DMD use was associated with worse QOL both physically and mentally, the decrease 
was probably not of clinical significance. Nonetheless, as some of the medications approved for MS have significant side effects and may well worsen QOL, our data suggest lifestyle modification may also be of benefit in ameliorating such negative effects, with the potential for adoption of healthy lifestyles to improve tolerance of the DMDs for those who take them.

Formal study of the QOL of people with MS who adopt these behaviours will provide the necessary evidence for their adoption in secondary preventive programs; however each of these factors is independently associated with improved QOL, with incrementally better QOL the healthier these behaviours, that is a dose-response association, lending weight to the likelihood of a causal association and encouragement to those willing to embrace them, whether or not they take DMDs. Weight loss also requires further study with respect to causality and in intervention studies as a secondary preventive measure in MS, with our study demonstrating significant associations of obesity with worse QOL. Structured programs to improve and increase social support and employment participation should also be studied in light of the demonstrated associations with QOL.

Primary care physicians may find it helpful to indicate to their patients with MS the magnitude of these differences in QOL for people with MS with healthy compared with unhealthy lifestyles. For example, our data indicate that comparing two people with MS with similar socio-demographics and disability, one who doesn't smoke, has a normal BMI and eats a wholefood diet low in saturated fat with frequent seafood scoring 90 points on the DHQ, with a high level of physical activity (such as swimming and running four days of the week for $45 \mathrm{~min}$ to an hour), without other illnesses, would score 30 points higher in physical QOL and 24 points higher in mental QOL compared with someone who smokes, is overweight, eats a typical Western diet with few vegetables or fruit scoring 60 on the DHQ, has a low level of physical activity, and has back pain and high blood pressure, commonly seen in people with such lifestyles. QOL differences of such magnitude are of great clinical significance.

\section{Limitations}

Our data were self-reported, and therefore accuracy cannot be verified. Each of the validated tools used has inherent limitations; we also used a number of researcher-devised questions not previously validated. The highly educated and relatively healthy nature of our sample may make our findings less generalizable. As this was an observational cross-sectional study, we cannot be clear about causality; the contribution of reverse causality may have been significant for some factors, such as physical activity, although it appears implausible for many of the associations noted, such as cigarette smoking and diet. Temporality may be a limitation, in that QOL was measured over the four weeks prior to the survey, whereas some of the other measures used different timeframes. Planned longitudinal follow up of the participants should provide evidence about temporality. Strengths of the study include the large sample representing over 50 countries and all clinical types of MS, enabling wide generalizability, and the absence of commercial interests, reducing potential for this bias.

\section{Conclusion}

Cigarette smoking, diet and exercise are associated with QOL for people with MS, both physically and mentally, with a dose-response effect for healthier diet and more exercise associated with increasingly better QOL, suggesting a causal relationship. Other lifestyle factors showed positive associations with QOL to a lesser extent, and DMD use a negative but probably clinically insignificant association. More research is required to clarify the magnitude and importance of these associations, and to incorporate lifestyle interventions into robust clinical trials. However, for optimal health status, lifestyle advice for people with MS appears warranted.

\section{Additional file}

Additional file 1: Table S1. Characteristics of the individuals with physical health composite missing and non-missing. Table S2. Associations between modifiable factors and physical and mental health composites obtained from multivariable regression models using multiple imputation. Table S3. Associations between modifiable factors and the recalculated physical health composite obtained from the multivariable regression model using complete case analysis. (DOCX $32 \mathrm{~kb}$ )

\section{Abbreviations}

DMDs: Disease-modifying drugs; HOLISM: Health outcomes and lifestyle in a sample of people with MS; IPAQ: International physical activity questionnaire; MHC: Mental health composite score; MS: Multiple sclerosis; MSQOL-

54: Multiple Sclerosis Quality of Life-54 instrument; PDDS: Patient Determined Disease Steps; PHC: Physical health composite score; QOL: Health-related quality of life; SCQ: Self-Administered Comorbidity Questionnaire; SF-36: 36 item short-form health survey; WHO: World Health Organisation

\section{Acknowledgements}

We thank the participants who provided their data for the study. The HOLISM study was funded by philanthropic donations from the Bloom Foundation and the Horne Family Foundation.

\section{Funding}

The study was funded by the Bloom Foundation and the Horne Family Charitable Trust

\section{Availability of data and material}

Data are stored as re-identifiable information at the University of Melbourne in the form of password-protected computer databases, and only the listed investigators have access to the data. All data have been reported on a group basis, summarising the group findings rather than individual findings so personal information cannot be identified. Therefore, we can supply 
aggregate group data on request. Readers may contact George Jelinek or Alysha De Livera.

\section{Authors' contributions}

Contributors GJ, CM and TW were responsible for study concept and design. $\mathrm{ADL}$ performed the statistical analysis. All authors assisted with data interpretation. GJ drafted the manuscript. All authors edited the manuscript and gave final approval for the manuscript to be published.

\section{Competing interests}

GJ receives royalties from his books Overcoming Multiple Sclerosis and Recovering from Multiple Sclerosis. GJ, SN and KT have received payments for conducting live-in educational workshops for people with MS.

\section{Consent for publication}

Not applicable.

\section{Ethics approval and consent to participate}

The Health Sciences Human Ethics Sub-Committee at the University of Melbourne provided ethical approval for the study (Ethics ID: 1545102) Participants were asked to read the participant information and to consent by clicking on a button to proceed to the survey.

\section{Received: 15 July 2016 Accepted: 15 November 2016} Published online: 22 November 2016

\section{References}

1. Grant WB, Riise T. Multiple sclerosis: A lifestyle disease? Neurology. 2016. 10.1212/WNL.0000000000002487.

2. Ford HL, Gerry E, Johnson MH, Tennant A. Health status and quality of life of people with multiple sclerosis. Disabil Rehabil. 2001;23(12):516-21.

3. Grima DT, Torrance GW, Francis G, Rice G, Rosner AJ, Lafortune L. Cost and health related quality of life consequences of multiple sclerosis. Mult Scler. 2000;6(2):91-8

4. Kaplan RM, Anderson JP. A general health policy model: update and applications. Health Serv Res. 1988;23(2):203-35.

5. Guyatt $\mathrm{GH}$, Feeny $\mathrm{DH}$, Patrick DL. Measuring health-related quality of life. Ann Intern Med. 1993;118(8):622-9.

6. Vickrey BG, Hays RD, Harooni R, Myers LW, Ellison GW. A health-related quality of life measure for multiple sclerosis. Qual Life Res. 1995;4(3): 187-206.

7. Rieckmann P, Boyko A, Centonze D, Elovaara I, Giovannoni G, Havrdova E, et al. Achieving patient engagement in multiple sclerosis: A perspective from the multiple sclerosis in the 21st Century Steering Group. Mult Scler Relat Disord. 2015:4(3):202-18.

8. Nortvedt MW, Riise T. The use of quality of life measures in multiple sclerosis research. Mult Scler. 2003;9(1):63-72.

9. Rudick RA, Miller DM. Health-related quality of life in multiple sclerosis: current evidence, measurement and effects of disease severity and treatment. CNS Drugs. 2008;22(10):827-39.

10. Baumstarck K, Boyer L, Boucekine M, Michel P, Pelletier J, Auquier P. Measuring the quality of life in patients with multiple sclerosis in clinical practice: a necessary challenge. Mult Scler Int. 2013;2013:524894.

11. Baumstarck K, Pelletier J, Butzkueven H, Fernandez O, Flachenecker P, Idiman $\mathrm{E}$, et al. Health-related quality of life as an independent predictor of long-term disability for patients with relapsing-remitting multiple sclerosis. Eur J Neurol. 2013;20(6):907-14.

12. Visschedijk MA, Uitdehaag BM, Klein M, van der Ploeg E, Collette EH, Vleugels $L$, et al. Value of health-related quality of life to predict disability course in multiple sclerosis. Neurol. 2004;63(11):2046-50.

13. Lysandropoulos AP, Havrdova E, Paradig MSG. 'Hidden' factors influencing quality of life in patients with multiple sclerosis. Eur J Neurol. 2015:22 Suppl 2:28-33.

14. Strober LB. Personality in multiple sclerosis (MS): impact on health, psychological well-being, coping, and overall quality of life. Psychol Health Med. 2016:18:1-10.

15. D'Alisa S, Miscio G, Baudo S, Simone A, Tesio L, Mauro A. Depression is the main determinant of quality of life in multiple sclerosis: A classificationregression (CART) study. Disabil Rehabil. 2006;28(5):307-14.
16. Goksel Karatepe A, Kaya T, Gunaydn R, Demirhan A, Ce P, Gedizlioglu M. Quality of life in patients with multiple sclerosis: the impact of depression, fatigue, and disability. Int J Rehabil Res. 2011;34(4):290-8.

17. Bauer UE, Briss PA, Goodman RA, Bowman BA. Prevention of chronic disease in the 21st century: elimination of the leading preventable causes of premature death and disability in the USA. Lancet. 2014;384(9937):45-52.

18. Filippini G, Munari L, Incorvaia B, Ebers GC, Polman C, D'Amico R, et al. Interferons in relapsing remitting multiple sclerosis: a systematic review. Lancet. 2003:361(9357):545-52.

19. Hadgkiss EJ, Jelinek GA, Weiland TJ, Pereira NG, Marck CH, van der Meer DM. The association of diet with quality of life, disability, and relapse rate in an international sample of people with multiple sclerosis. Nutr Neurosci. 2015:18(3):125-36

20. Jelinek GA, Hadgkiss EJ, Weiland TJ, Pereira NG, Marck CH, van der Meer DM. Association of fish consumption and Omega 3 supplementation with quality of life, disability and disease activity in an international cohort of people with multiple sclerosis. Int J Neurosci. 2013;123(11):792-800.

21. Jelinek GA, Marck CH, Weiland TJ, Pereira N, van der Meer DM, Hadgkiss EJ. Latitude, sun exposure and vitamin D supplementation: associations with quality of life and disease outcomes in a large international cohort of people with multiple sclerosis. BMC Neurol. 2015;15:132.

22. Marck CH, Hadgkiss EJ, Weiland TJ, van der Meer DM, Pereira NG, Jelinek GA. Physical activity and associated levels of disability and quality of life in people with multiple sclerosis: a large international survey. BMC Neurol. 2014;14:143.

23. Weiland TJ, Hadgkiss EJ, Jelinek GA, Pereira NG, Marck CH, van der Meer DM. The association of alcohol consumption and smoking with quality of life, disability and disease activity in an international sample of people with multiple sclerosis. J Neurol Sci. 2014;336(1-2):211-9.

24. Marck CH, Neate SL, Taylor KL, Weiland TJ, Jelinek GA. Prevalence of Comorbidities, Overweight and Obesity in an International Sample of People with Multiple Sclerosis and Associations with Modifiable Lifestyle Factors. PLoS One. 2016;11(2):e0148573.

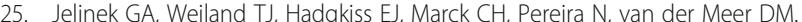
Medication use in a large international sample of people with multiple sclerosis: associations with quality of life, relapse rate and disability. Neurol Res. 2015;37(8):662-73.

26. Hadgkiss EJ, Jelinek GA, Weiland TJ, Pereira NG, Marck CH, van der Meer DM. Methodology of an International Study of People with Multiple Sclerosis Recruited through Web 2.0 Platforms: Demographics, Lifestyle, and Disease Characteristics. Neurol Res Int. 2013:2013:580596.

27. Hohol MJ, Orav EJ, Weiner HL. Disease steps in multiple sclerosis: a simple approach to evaluate disease progression. Neurol. 1995:45(2):251-5.

28. Sangha O, Stucki G, Liang MH, Fossel AH, Katz JN. The Self-Administered Comorbidity Questionnaire: a new method to assess comorbidity for clinical and health services research. Arthritis Rheum. 2003;49(2):156-63.

29. McKellar S, Horsley P, Chambers R, Pullen M, Vendersee P, Clarke C, et al. Development of the diet habits questionnaire for use in cardiac rehabilitation. Aust J Primary Health. 2008;14(3):43-7.

30. Blake R, McKay D. A single-item measure of social supports as a predictor of morbidity. J Fam Pract. 1986:22(1):82-4.

31. Craig CL, Marshall AL, Sjostrom M, Bauman AE, Booth ML, Ainsworth BE, et al. International physical activity questionnaire: 12-country reliability and validity. Med Sci Sports Exercise. 2003;35(8):1381-95.

32. Van Buuren S, Brand JP, Groothuis-Oudshoorn CGM, Rubin DB. Fully conditional specification in multivariate imputation. Journal of statistical computation and simulation. J Statist Comput Simul. 2006;76(12):1049-64.

33. Schafer JL. Analysis of incomplete multivariate data. Cox DR, Isham V, Keiding N, Reid N, Tong H, eds. Florida: Chapman and Hall/CRC; 1997

34. Kappos L, Gold R, Arnold DL, Bar-Or A, Giovannoni G, Selmaj K, et al. Quality of life outcomes with BG-12 (dimethyl fumarate) in patients with relapsingremitting multiple sclerosis: the DEFINE study. Mult Scler. 2014;20(2):243-52.

35. Spelman T, Gray O, Trojano M, Petersen T, Izquierdo G, Lugaresi A, et al. Seasonal variation of relapse rate in multiple sclerosis is latitude dependent Ann Neurol. 2014;76(6):880-90

36. Bueno AM, Sayao AL, Yousefi M, Devonshire V, Traboulsee A, Tremlett H. Health-related quality of life in patients with longstanding 'benign multiple sclerosis'. Mult Scler Relat Disord. 2015:4(1):31-8.

37. Stradling C, Hamid M, Fisher K, Taheri S, Thomas GN. A review of dietary influences on cardiovascular health: part 1: the role of dietary nutrients. Cardiovasc Hematol Disord Drug Targets. 2013;13(3):208-30. 
38. Yamout B, Issa Z, Herlopian A, El Bejjani M, Khalifa A, Ghadieh AS, et al. Predictors of quality of life among multiple sclerosis patients: a comprehensive analysis. Eur J Neurol. 2013;20(5):756-64.

39. Ramanujam R, Hedstrom AK, Manouchehrinia A, Alfredsson L, Olsson T, Bottai M, et al. Effect of Smoking Cessation on Multiple Sclerosis Prognosis. JAMA Neurol. 2015;72(10):1117-23.

40. Kern S, Ziemssen T. Brain-immune communication psychoneuroimmunology of multiple sclerosis. Mult Scler. 2008;14(1):6-21.

41. Riccio P, Rossano R. Nutrition facts in multiple sclerosis. ASN Neuro. 2015;7:1.

42. Bragazzi NL. The Gap in the Current Research on the Link between Health Locus of Control and Multiple Sclerosis: Lessons and Insights from a Systematic Review. Mult Scler Int. 2013;2013:972471.

43. Taylor KL, Hadgkiss EJ, Jelinek GA, Weiland TJ, Pereira NG, Marck CH, et al. Lifestyle factors, demographics and medications associated with depression risk in an international sample of people with multiple sclerosis. BMC Psychiatry. 2014;14:327.

44. Weiland TJ, Jelinek GA, Marck CH, Hadgkiss EJ, van der Meer DM, Pereira $\mathrm{NG}$, et al. Clinically significant fatigue: prevalence and associated factors in an international sample of adults with multiple sclerosis recruited via the internet. PLoS One. 2015;10(2):e0115541.

45. Vuger-Kovacic D, Gregurek R, Kovacic D, Vuger T, Kalenic B. Relation between anxiety, depression and locus of control of patients with multiple sclerosis. Mult Scler. 2007;13(8):1065-7.

\section{Submit your next manuscript to BioMed Central and we will help you at every step:}

- We accept pre-submission inquiries

- Our selector tool helps you to find the most relevant journal

- We provide round the clock customer support

- Convenient online submission

- Thorough peer review

- Inclusion in PubMed and all major indexing services

- Maximum visibility for your research

Submit your manuscript at www.biomedcentral.com/submit

) Biomed Central 